\title{
Regional aspects of modelling burned areas in Europe
}

Andrey Krasovskii ${ }^{*}$, Nikolay Khabarov ${ }^{1}$, Mirco Migliavacca ${ }^{2}$, Florian Kraxner $^{1}$, Michael Obersteiner ${ }^{1}$

1- International Institute for Applied Systems Analysis, Schlossplatz 1, 2361 Laxenburg, Austria

2- Max Planck Institute for Biogeochemistry, Hans-Knöll-Str. 10, 07745 Jena, Germany

Abstract: This paper presents a series of improvements to the quantitative modelling of burned areas in Europe under historical climate. The Standalone Fire Model (SFM) based on a state-of-the-art large scale mechanistic fire modelling algorithm is used to reproduce historical burned areas reported in the two publicly available datasets - European Forest Fire Information System (EFFIS) and Global Fire Emissions Database (GFED). The most recent versions of these sources allow a broader validation of SFM's modelled burned areas at a country level. Our analysis is carried out for the years 2000-2008 for 17 European countries utilizing both EFFIS and GFED datasets for model benchmarking. We suggest improving the original model by modifying the fire probability function reflecting fuel moisture. This modification allows for a dramatic improvement of accuracy in modelled burned areas for a range of European countries. We also explore in detail a pixel-level parametrization of firefighting efficiency in SFM along with modifications of the biomass map. In comparison with the aggregated country-level approach, the advantages of the finer calibration are quite minor for the most recent version of the GFED dataset. Overall, the annual burned areas modelled by this improved SFM version are in good agreement with historical observations.

Brief summary: This paper presents a series of improvements to the quantitative modelling of burned areas in Europe under historical climate. Our analysis is carried out for 2000-2008 for 17 European countries. The annual burned areas modelled by an improved version of the Standalone Fire Model (SFM) are in good agreement with historical observations.

Additional keywords: fire model, fuel moisture, probability of fire, validation.

\section{Introduction and background}

Fires affect terrestrial ecosystems and have profound consequences on global climate, air quality, and vegetation (Bowman et al. 2009; Marlier et al. 2012). In Europe alone, fires impact more than half a million hectares annually (San-Miguel-Ayanz and Camia 2010). Although fire is required for the natural seeding of plant species in some (e.g. Mediterranean) ecosystems (Vélez 1990), the aggregate consequences of large-scale destruction are overwhelmingly negative: fires can lead to large economic damage and loss of life (San-MiguelAyanz and Camia 2010).

Carbon emissions from fires contribute substantially to the present day global greenhouse gases (GHG) balance (Bowman et al. 2009; Migliavacca et al. 2013a). The total area burned and fire intensity are projected to increase in a warming climate, which in turn will increase carbon emissions from wildfires (IPCC 2013). However, this phenomena is rather complex: fires generate net emissions in the short-term, but in the longer term they can lead to a negative, neutral or positive carbon balance by converting part of the burned biomass into pyrogenic organic matter as demonstrated for a typical boreal forest fire (Santín et al. 2015).

In the climate change mitigation context, changes in fire frequency may jeopardize the benefits achieved through reducing emissions from deforestation and degradation (REDD+) programs, as the carbon savings

\footnotetext{
${ }^{*}$ Corresponding author, e-mail: krasov@iiasa.ac.at
} 
achieved by avoiding deforestation may be partially negated by increased emissions from fires (Aragao and Shimabukuro 2010). Ignoring interactions between forest degradation and fire risk could lead to underestimating the potential benefits of REDD+ programs (in tropical forests in particular), and result in mischaracterization of associated processes and costs (Lubowski and Rose 2013). Investments in REDD+ programs may ultimately fail to achieve emission reductions unless they also reduce the risk of fires (Barlow et al. 2012). Thus, modelling temporal and spatial complexities of fire dynamics and related risks is not only important for current conditions, but also for projected climate change impacts and mitigation potential assessments and, in particular, for REDD+.

Fire regimes are determined by climate, vegetation, and direct human influence. Climate is recognized as a major determinant of fire patterns on a global scale (Marlon et al. 2008). In Europe, human activities including negligence and arson cause more than 95\% of wildfires (Ganteaume et al. 2012; San-Miguel-Ayanz et al. 2012). At the same time, overall trends are closely linked to weather conditions (Rego et al. 2010), and climatic, socioeconomic, and landscape fire drivers should be considered together to better understand inter-annual variations in burned areas (Costa et al. 2010).

This study explores the possibilities to advance state-of-the-art in modelling of total burned areas in Europe by utilizing the Standalone Fire Model (SFM) (Khabarov et al. 2014). The SFM is based on a process-based fire parameterization algorithm that was specifically developed for dynamic global vegetation models (Arora and Boer 2005) and was later modified and integrated as a module within the Community Land Model (CLM) (Kloster et al. 2010). The augmented CLM was used to estimate climate impact on fires on a global scale (Kloster et al. 2012), and later was refined and parameterized for the application over Europe evolving to the CLM-AB model (Migliavacca et al. 2013b). The CLM-AB model was selected as a basis for SFM because it is able to capture the complex interactions among burned area, climate, and fuel variability in Europe (Migliavacca et al. 2013b). Modifications and calibration procedures implemented in SFM address the systematic overestimation of burned areas by the CLM-AB (Khabarov et al. 2014). The key features implemented in SFM include fuel moisture computation based on the Canadian Fine Fuel Moisture Code (FFMC) index (Van Wagner and Pickett 1985) and a procedure for calibrating fire suppression efficiency.

The SFM is employed to reproduce burned areas at a country scale for historical climate. The observed burned areas are reported in two publicly available datasets - the European Forest Fire Information System ${ }^{1}$ (EFFIS) (Schmuck et al. 2014) and the Global Fire Emissions Database version 4.0 (GFED) (Giglio et al. 2013). Our analysis is carried out for the years 2000-2008 for 17 European countries. With a focus on country-level results, we implemented a procedure to calibrate country-specific fire suppression efficiency (Khabarov et al. 2014). We subsequently describe in detail and discuss the benefits of our suggested extension of the original SFM model through: (1) modifying the fire probability function reflecting fuel moisture, and (2) detailed pixel-level parametrization of the firefighting efficiency along with modifications to the biomass map.

\section{Methods and data}

The SFM operates with a daily time step and a spatial resolution of $25 \times 25 \mathrm{~km}$. All inputs in the SFM are adjusted as necessary to fit this resolution. For SFM runs on historical climate, we use the Princeton dataset ${ }^{2}$

${ }^{1}$ Data from the European Fire Database is available at http://forest.jrc.ec.europa.eu/effis/applications/dataand-services/

${ }^{2}$ http://hydrology.princeton.edu/data.pgf.php 
(Sheffield et al. 2006). This global dataset of meteorological forcing has a spatial resolution of 1 arc degree and for the time span of 1948-2008 provides historical daily values of temperature, precipitation, wind, specific humidity, and surface pressure. Relative humidity, which is needed for the moisture calculation implemented through FFMC (Van Wagner and Pickett 1985), was derived from temperature, specific humidity, and surface pressure by utilizing a saturation vapour pressure approximation (Flatau et al. 1992). For the population density dataset, we used the Gridded Population of the World GPW version 3 (CIESIN 2005). Following the CLM-AB's fuel representation approach (Migliavacca et al. 2013b), we defined fuel available for burning as a combination of litter and coarse woody debris (CWD) pools, excluding stem biomass. We used dead wood (as the best available proxy for CWD at the spatial scale of interest) and litter carbon data from the Global Forest Biomass map (Kindermann et al. 2008) - a half degree global spatial dataset. The use of static biomass data, fuel description by a single parameter (biomass available for burning) without separating fuel type, and excluding lightning as an ignition source are all among current simplifications of the SFM's modelling approach.

Fire suppression efficiency depends on a number of factors, including local regulations and available resources, and varies from one country to another. In SFM as in the original fire algorithm (Arora and Boer 2005) the efficiency of fire suppression is defined as the probability $q$ of extinguishing a fire on a given day. Potential area burned within one day and the cumulative burned area over any time period (for a grid pixel or an entire country) can be represented as

$$
A(q)=a(1-q)(2-q) / q^{2},
$$

where the coefficient $a$ reflects availability of fuel, ignition sources, and weather conditions, but is not a function of $q$ (Arora and Boer 2005; Kloster et al. 2010). In our calibration procedure, we find a value of the variable $q=$ $q_{c}$ such that $A\left(q_{c}\right)=A_{o b s}$, where $A_{o b s}$ is the observed cumulative burned area in a specific country over a given time period. Based on a non-calibrated model run with an arbitrary value of $q=q_{0}\left(0<q_{0}<1\right)$ delivering accumulated burned area $A\left(q_{0}\right)$ for a time period for a given country, the calibrated value $q_{c}$ is defined by the following equation:

$$
q_{c}=\frac{-3+\sqrt{8 \beta+1}}{2(\beta-1)} \text {, where } \beta=\frac{A_{o b s}}{A\left(q_{0}\right)}\left(1-q_{0}\right)\left(2-q_{0}\right) / q_{0}^{2} .
$$

Substituting the value $A\left(q_{0}\right)(1)$ into equation (2), we see that the parameter $\beta$ equals $A_{o b s} / a$ and therefore the calibrated value of suppression efficiency $q_{c}$ does not depend on the arbitrary selected value $q_{0}$. Nevertheless, model runs with a determinate (placeholding) value for $q_{0}$ are necessary to obtain the value of $a$.

We apply this calibration procedure at a country-level, forcing the model to fit the total accumulated burned area (as reported in the most recent versions of both EFFIS and GFED data sets) over the entire nine-year time period 2000-2008, which is long enough relative to the model's operating daily time step. The EFFIS dataset provides yearly burned areas for 17 European countries in the chosen historical period. We use these 17 countries to validate the model on both GFED and EFFIS datasets by analyzing the agreement between reported and modelled annual burned areas for each country. We also explore the benefits of a more detailed, spatially-explicit (pixellevel) calibration of $q$ based on the GFED data (at 0.25 arc degree spatial resolution).

Our analysis indicated that for some countries there is a spatial inconsistency between the GFED data and the biomass map: there are pixels where burned areas are reported in GFED, but there are no fires according to SFM outputs due to zero probability $P_{b}$ of fire related to biomass availability (Kloster et al. 2010). This probability in the model is represented as:

$$
P_{b}=\max \left[0, \min \left(1, \frac{F-F_{l}}{F_{u}-F_{l}}\right)\right],
$$

where $F_{l}=200 \frac{g C}{m^{2}}, F_{u}=1000 \frac{g C}{m^{2}}$ are lower and upper thresholds, and $F$ is the aboveground biomass available 
for burning.

We consider the pixels where burned area is reported $\left(A_{o b s}>0\right.$ in equation (2)), and at the same time the probability of fire conditional on biomass $P_{b}=0$, meaning that there is not enough biomass for a fire to occur ( $F \leq F_{l}$ in equation (3)). Consequently, in these pixels the burned area calculated by SFM is zero $\left(A\left(q_{0}\right)=0\right)$ which makes the calibration procedure (see equation (2)) impossible. To overcome the problem of spatial disagreement between SFM's biomass map and GFED, we implemented a supplementary procedure of biomass modification within these "invalid" pixels by setting it to the average level between the thresholds $F_{l}$ and $F_{u}$, i.e. $F=$ $600 \mathrm{gC} / \mathrm{m}^{2}$. This procedure achieves spatial consistency between GFED and SFM in the historical period.

Finally, we investigated the possibility of improving SFM by modifying the function describing the dependence of fire probability on fuel moisture. The original function in the CLM model (Kloster et al. 2010) is given by the formula:

$$
P_{m}=1-\tanh \left(1.75 \frac{m}{m_{e}}\right)^{2}
$$

where $m$ is the plant-available volumetric water content in the top $5 \mathrm{~cm}$ of the soil, $m$ (ratio between 0 and 1 ) is used as a surrogate for fuel moisture content (Thonicke et al. 2001), and $m_{e}$ (ratio between 0 and 1 ) is the moisture of extinction, set to 0.35, independent of fuel type (Kloster et al. 2010). The moisture of extinction is the threshold of fuel moisture content above which a fire is unlikely to spread. In temperate ecosystems, the reported moisture of extinction for dead fuel is within the range of 15-30\% (Albini 1976). In Thonicke et al. (2001), fire is considered to be absent if the probability to spread is below 5\%. For the exponential power function developed for Central Portugal $m_{e}=0.3$ (Thonicke et al. 2001).

In our regional model we substituted (4) by the following function:

$$
P_{m}=1-\tanh \left(1.75 \frac{m}{m_{e}}\right) \text {, }
$$

and set the moisture of extinction to a value of $m_{e}=0.2$, which is consistent with Albini (1976). This modified function provides a sharper dependence of fire probability on moisture (see Figure 1). In Equation (5), $P_{m}\left(m \geq m_{e}\right) \approx 5 \%$ is consistent with the moisture of extinction definition in Thonicke et al. (2001) - and $P_{m}(m \geq 0.35) \approx 0$, is still consistent with Kloster et al. (2010). The parameter $m_{e}=0.2$ in Equation (5) should be considered as a rather technical constant value, since its primary purpose is to describe the probability function as such; the fact that it also reflects the moisture of extinction definition is rather a coincidence. The value $m_{e}=$ 0.2 in Equation (5) was chosen empirically to improve the model performance as compared to the original model based on Equation (4).

\section{Results and discussion}

By construction, the SFM country-level calibration procedure guarantees an exact agreement between simulated and reported cumulative burned areas over the entire historical nine-year period 2000-2008. However, as demonstrated below, the model describes reasonably well the inter-annual variability of burned areas.

Table 1 reports performance of the SFM model (GFED and EFFIS calibrated) with the standard moisture-fire probability function (Equation (4)) in terms of burned area for 17 countries: Italy, Portugal, Spain, France, Germany, Poland, Sweden, Greece, Bulgaria, Switzerland, Finland, Croatia, Lithuania, Latvia, Romania, Slovakia, and Turkey. We have selected these countries because their data as reported in EFFIS cover the entire period 20002008. An evaluation of GFED with EFFIS data is also included for comparison in Table 1. Similar to Khabarov et al. (2014), based on the annual values for the historical period 2000-2008, we report mean absolute error (MAE) in thousands of hectares and Pearson's correlation coefficient $r$. Below, when the SFM model is calibrated on 
GFED data, it is compared to GFED data (SFM vs GFED), and when the SFM model is calibrated on EFFIS data, it is compared with EFFIS data (SFM vs EFFIS). Generally, the agreement of either the SFM model with EFFIS data, or the SFM model with GFED data, is comparable or superior to the agreement between GFED and EFFIS. Let us note that Romania and Turkey can definitively be classified as outliers in the analysis due to the high disagreement in burned areas for these countries between GFED and EFFIS datasets.

While calibrated on a country-level, the SFM has problems reproducing historical burned areas for several countries. Namely, according to Table 1, one could envision potential improvements for the following seven countries: Italy, Portugal, Spain, France, Sweden, Greece, and Croatia. For all other 10 countries SFM is closer to either GFED or EFFIS than these datasets are to each other. Below we try other calibration approaches and take the results of agreement presented in Table 1 as a benchmark for estimating model improvement.

We used the spatial GFED dataset to perform a pixel-level calibration on the considered nine-year time interval (2000-2008). The results of the pixel-level calibration with biomass substitution are indicated in Table 2. The indicators which improve relative to the country-level GFED calibration (Table 1) are marked in bold font. Although pixel-calibration improved indicators for several countries, e.g. Germany, Sweden, Lithuania, Latvia, and Romania, we note that it does not provide significant improvements. This can be explained by the fact that the SFM's agreement with GFED is in general considerably weaker than with EFFIS, and this approach is not able to resolve the underlying disagreement.

Results generated by the SFM model with the modified moisture-fire probability function (Equation (4)) are shown in Table 3. Here we outlined improvements compared to the same country-level calibrated SFM with the original probability function (4) presented in Table 1. One can see in Table 3 that in 10 out of 17 countries both indicators (MAE and Pearson's correlation coefficient) are better for at least one of the observational datasets (EFFIS and GFED). Notably, we improved results for Italy where SFM agreement with EFFIS became better than the agreement between EFFIS and GFED (Table 1). Remarkable results are achieved for Switzerland, Croatia, France, Germany, Slovakia, and Finland, where Pearson's correlation coefficient is above 0.9. Relative changes in MAE and Pearson's coefficient between the SFM model with the modified function and the original one are given as percentages in Table 4. One can see that for Spain and Poland the SFM model with the original function (4) performs better. The new function (5) leads to an improvement for Portugal in terms of MAE, while Pearson's coefficient is almost unchanged. Improvements in Pearson's correlation coefficient for Lithuania, Latvia, and Slovakia are accompanied by a simultaneous increase in MAE. For Sweden, the improvement in Pearson's coefficient is $121 \%$, and for Switzerland MAE is decreased by $82 \%$. The positive results of this experiment might hint to potential improvements in the performance of the model when country-specific probability functions are applied. As fuels differ from one country to another, this approach might be a promising way to incorporate such heterogeneity within the existing modelling framework, which has a rather aggregated representation of fuel.

Based on the results of different calibration approaches to the SFM model given in Tables 1-3, we can choose the best calibration approach for each country. In this way, the agreement (as measured by both MAE and Pearson's coefficient) between the SFM model and either the GFED or EFFIS dataset is superior to the agreement between the two datasets in 13 out of 17 countries. The model underperforms as compared to GFED-EFFIS for Greece and Portugal (both MAE and $r$ ), Spain ( $r$ ), and France (MAE).

In Figure 2, we show yearly dynamics of burned areas for each country (including two outliers: Romania and Turkey) to graphically compare outputs of the SFM model against EFFIS and GFED datasets. One can see that for some countries disagreement between GFED and EFFIS is high, e.g. plots for Spain, Germany, Poland, Sweden, Bulgaria, Switzerland, and Lithuania. Nevertheless, calibrated SFM model shows reasonable yearly dynamics for 
these countries, and disagreement between the SFM model and EFFIS or GFED datasets for these countries is comparable with disagreement between EFFIS and GFED. The SFM model is able to catch annual peaks, e.g. in plots for Italy, France, Switzerland, Finland, Croatia, Latvia, and Slovakia. This ability is confirmed by high Pearson's correlation coefficients in Table 3. However, when the magnitude of the peaks is high, the SFM model underestimates burned areas for such extreme years. This limitation, which can be seen in the plots for Portugal, is an example of the general difficulty mechanistic fire models suffer in simulating burned area for years with severe fire seasons.

\section{Conclusions}

In this paper we performed a broader validation of SFM developed in (Khabarov et al. 2014) applying both country- and pixel-level calibration of the model. We suggested an improvement of the original model through: (i) modification of the fire probability function depending on fuel moisture, and (ii) detailed pixel-level parametrization of firefighting efficiency in SFM along with modifications of the biomass map. We analyzed 17 European countries using the most recent EFFIS and GFED datasets in the historical period 2000-2008. On the basis of this analysis, we identified a high disagreement between EFFIS and GFED for Romania and Turkey. We found that the advantages of finer pixel-level calibration techniques are quite minor relative to the aggregated country-level approach. On the other hand, the new functional form of the probability of fire reflecting fuel moisture leads to a considerable improvement in the modelling of historical burned areas. In 10 out of 17 countries, the agreement of the SFM model with GFED or EFFIS data was improved for both indicators MAE and Pearson's correlation coefficient simultaneously. For these countries, the relative improvement in MAE was $9 \%$ to $82 \%$, and in Pearson's correlation coefficient $2 \%$ to $121 \%$. These results open possibilities for further research focusing on the country-specific fire probability functions. To illustrate the agreement of burned areas modelled by the SFM with the historical data provided by EFFIS and GFED, we presented temporal dynamics of annual burned areas over the historical period. The figures illustrate the level of agreement between the SFM model and the EFFIS and GFED datasets, respectively, which is comparable to the agreement between EFFIS and GFED. Overall, the proposed approach to calibrate the SFM model improves the accuracy of modelling burned areas on a country scale in Europe. In a broader application perspective, the improved calibration approach based on historical data is an important step in tuning the SFM model for projecting burned areas in the future under the uncertainties associated with climate change scenarios as well as modelling adaptation options (Khabarov et al. 2014). Finally, improved modelling of regional burned areas and assessment of corresponding $\mathrm{CO}_{2}$ emissions (Migliavacca et al. 2013a) could help to adequately represent risks of wildland fires in REDD+ programs (Lubowski and Rose 2013) as well as in the wider mitigation and risk management context.

\section{Acknowledgements}

This research has received financial support from the project "Options Market and Risk-Reduction Tools for REDD+" funded by the Norwegian Agency for Development Cooperation under agreement number QZA-0464 QZA-13/0074, and was also supported by the European Commission, Seventh Framework Programme under grant agreement No. 603906 (ECONADAPT). We thank anonymous reviewers for their useful comments and suggestions and also Ruben Lubowski, Brian Walsh, Cynthia Festin, Elena Moltchanova, and Anatoly Shvidenko for discussions, reviews, and helpful comments.

\section{References}

Albini FA (1976) Estimating wildfire behaviour and effects. Intermountain Forest and Range Experiment Station, Forest Service, U.S. Department of Agriculture, USDA Forest Service General Technical Report INT-3. (Ogden, Utah) 
Aragao LEOC, Shimabukuro YE (2010) The Incidence of Fire in Amazonian Forests with Implications for REDD. Science 328(5983), 1275-1278. doi:10.1126/science.1186925.

Arora VK, Boer GJ (2005) Fire as an interactive component of dynamic vegetation models. Journal of geophysical research 110(G2), G02008. http://www.agu.org/pubs/crossref/2005/2005JG000042.shtml.

Barlow J, Parry L, Gardner TA, Ferreira J, Aragão LEOC, Carmenta R, Berenguer E, Vieira ICG, Souza C, Cochrane MA (2012) The critical importance of considering fire in REDD+ programs. Biological Conservation 154, 1-8. doi:10.1016/j.biocon.2012.03.034.

Bowman DMJS, Balch JK, Artaxo P, Bond WJ, Carlson JM, Cochrane MA, D’Antonio CM, DeFries RS, Doyle JC, Harrison SP, Johnston FH, Keeley JE, Krawchuk MA, Kull CA, Marston JB, Moritz MA, Prentice IC, Roos CI, Scott AC, Swetnam TW, van der Werf GR, Pyne SJ (2009) Fire in the Earth System. Science 324(5926), 481-484. doi:10.1126/science.1163886.

CIESIN (2005) Gridded Population of the World Version 3 (GPWv3): Population Density Grids. Center for International Earth Science Information Network (CIESIN), Columbia University; and Centro Internacional de Agricultura Tropical (CIAT), Palisades, NY: Socioeconomic Data and Applications Center (SEDAC), Columbia University. http://sedac.ciesin.columbia.edu/gpw.

Costa L, Thonicke K, Poulter B, Badeck F-W (2010) Sensitivity of Portuguese forest fires to climatic, human, and landscape variables: subnational differences between fire drivers in extreme fire years and decadal averages. Regional Environmental Change 11(3), 543-551. doi:10.1007/s10113-010-0169-6.

Flatau PJ, Walko RL, Cotton WR (1992) Polynomial Fits to Saturation Vapor Pressure. Journal of Applied Meteorology 31(12), 1507-1513. doi:10.1175/1520-0450(1992)031<1507:PFTSVP>2.0.CO;2.

Ganteaume A, Camia A, Jappiot M, San-Miguel-Ayanz J, Long-Fournel M, Lampin C (2012) A review of the main driving factors of forest fire ignition over Europe. Environmental management 1-12. http://link.springer.com/article/10.1007/s00267-012-9961-z.

Giglio L, Randerson JT, van der Werf GR (2013) Analysis of daily, monthly, and annual burned area using the fourth-generation global fire emissions database (GFED4). Journal of Geophysical Research: Biogeosciences 118(1), 317-328. doi:10.1002/jgrg.20042.

IPCC (2013) Working Group I Contribution to the IPCC Fifth Assessment Report Climate Change 2013: The Physical Science Basis (Final Draft Underlying Scientific- Technical Assessment).

Khabarov N, Krasovskii A, Obersteiner M, Swart R, Dosio A, San-Miguel-Ayanz J, Durrant T, Camia A, Migliavacca M (2016) Forest fires and adaptation options in Europe. Regional Environmental Change 16(1), 21-30. doi:10.1007/s10113-014-0621-0.

Kindermann GE, McCallum I, Fritz S, Obersteiner M (2008) A global forest growing stock, biomass and carbon map based on FAO statistics. Silva Fennica 42(3), 244.

Kloster S, Mahowald NM, Randerson JT, Lawrence PJ (2012) The impacts of climate, land use, and demography on fires during the 21st century simulated by CLM-CN. Biogeosciences 9(1), 509-525. doi:10.5194/bg9-509-2012.

Kloster S, Mahowald NM, Randerson JT, Thornton PE, Hoffman FM, Levis S, Lawrence PJ, Feddema JJ, Oleson KW, Lawrence DM (2010) Fire dynamics during the 20th century simulated by the Community Land Model. Biogeosciences 7, 1877-1902. http://www.biogeosciences.net/7/1877/2010/

Lubowski RN, Rose SK (2013) The Potential for REDD+: Key Economic Modeling Insights and Issues. Review of Environmental Economics and Policy 7(1), 67-90. doi:10.1093/reep/res024.

Marlier ME, DeFries RS, Voulgarakis A, Kinney PL, Randerson JT, Shindell DT, Chen Y, Faluvegi G (2012) El Niño and health risks from landscape fire emissions in southeast Asia. Nature Climate Change 3(2), 131136. doi:10.1038/nclimate1658. 
Marlon JR, Bartlein PJ, Carcaillet C, Gavin DG, Harrison SP, Higuera PE, Joos F, Power MJ, Prentice IC (2008) Climate and human influences on global biomass burning over the past two millennia. Nature Geoscience 1(10), 697-702. doi:10.1038/ngeo313.

Migliavacca M, Dosio A, Camia A, Hobourg R, Houston-Durrant T, Kaiser JW, Khabarov N, Krasovskii AA, Marcolla B, San Miguel-Ayanz J, Ward DS, Cescatti A (2013a) Modeling biomass burning and related carbon emissions during the 21st century in Europe. Journal of Geophysical Research: Biogeosciences 118(4), 1732-1747. doi:10.1002/2013JG002444.

Migliavacca M, Dosio A, Kloster S, Ward DS, Camia A, Houborg R, Houston-Durrant T, Khabarov N, Krasovskii AA, San Miguel-Ayanz J, Cescatti A (2013b) Modeling burned area in Europe with the Community Land Model. Journal of Geophysical Research: Biogeosciences 118(1), 265-279. doi:10.1002/jgrg.20026.

Rego F, Rigolot E, Fernandes P, Montiel C, Silva JS (2010) 'Towards Integrated Fire Management. European Forest Institute Policy Brief.' (Joensuu, Finland) http://www.efi.int/files/attachments/publications/efi_policy_brief_4_en.pdf.

San-Miguel-Ayanz J, Camia A (2010) Forest Fires. In: Mapping the impacts of natural hazards and technological accidents in Europe An overview of the last decade. EEA Technical Report N13/2010. doi:10.2800/62638.

San-Miguel-Ayanz J, Schulte E, Schmuck G, Camia A, Strobl P, Liberta G, Giovando C, Boca R, Sedano F, Kempeneers P, McInerney D, Withmore C, de Oliveira SS, Rodrigues M, Durrant T, Corti P, Oehler F, Vilar L, Amatulli G (2012) Comprehensive monitoring of wildfires in Europe: The European Forest Fire Information System (EFFIS) In: Approaches to Managing Disaster - Assessing Hazards, Emergencies and Disaster Impacts. InTech (J Tiefenbacher, Ed.). doi:10.5772/28441.

Santín C, Doerr SH, Preston CM, González-Rodríguez G (2015) Pyrogenic organic matter production from wildfires: a missing sink in the global carbon cycle. Global Change Biology 21(4), 1621-1633. doi:10.1111/gcb.12800.

Schmuck G, San-Miguel-Ayanz J, Camia A, Durrant TH, Boca R, Libertá G, Petroliagkis T, Di Leo M, RodriguezAseretto D, Boccacci F, Schulte E (2014) Forest Fires in Europe, Middle East and North Africa 2013. Joint Research Centre, Institute for Environment and Sustainability, EUR 26791 EN. (Luxembourg: Publications Office of the Union) http://forest.jrc.ec.europa.eu/media/cms_page_media/9/FireReport2013_final2pdf_2.pdf.

Sheffield J, Goteti G, Wood EF (2006) Development of a 50-year high-resolution global dataset of meteorological forcings for land surface modeling. Journal of Climate 19(13), 3088-3111.

Thonicke K, Venevsky S, Sitch S, Cramer W (2001) The role of fire disturbance for global vegetation dynamics: coupling fire into a Dynamic Global Vegetation Model. Global Ecology and Biogeography 10(6), 661677. http://onlinelibrary.wiley.com/doi/10.1046/j.1466-822X.2001.00175.x/full.

Vélez R (1990) Mediterranean forest fires: A regional perspective. Unasylva 41(162), 3-9. http://www.fao.org/docrep/t9500e/t9500e02.htm.

Van Wagner CE, Pickett TL (1985) 'Equations and FORTRAN program for the Canadian Forest Fire Weather Index System.’ (Canadian Forestry Service, Petawawa National Forestry Institute: Chalk River, Ontario) http://cfs.nrcan.gc.ca/publications/?id=19973. 
Tables

Table 1. SFM performance in terms of modelled annual burned areas for the historical period 2000-2008 for selected countries. GFED and EFFIS data were used for model calibration and consecutive benchmarking using the respective dataset. $r$ is Pearson's correlation coefficient, and MAE is the mean absolute error (in thousands of hectares). Best values by country are highlighted in bold.

\begin{tabular}{||l||r|r||r|r|r|r||}
\hline \multicolumn{1}{||l||}{} & \multicolumn{2}{l|}{ SFM vs EFFIS } & \multicolumn{2}{l|}{ SFM vs GFED } & \multicolumn{2}{l|}{ GFED vs EFFIS } \\
\hline \hline Country & MAE & \multicolumn{1}{l|}{$\boldsymbol{r}$} & \multicolumn{1}{l|}{ MAE } & \multicolumn{1}{l|}{$\boldsymbol{l}$} & \multicolumn{1}{l|}{ MAE } & \multicolumn{1}{r|}{} \\
\hline \hline Italy & 28.38 & 0.672 & 32.24 & 0.477 & $\mathbf{2 8 . 0 8}$ & $\mathbf{0 . 7 8 1}$ \\
\hline Portugal & 84.09 & 0.766 & 97.45 & 0.772 & $\mathbf{2 4 . 5 4}$ & $\mathbf{0 . 9 8 7}$ \\
\hline Spain & $\mathbf{2 7 . 7 8}$ & 0.691 & 42.63 & 0.428 & 30.27 & $\mathbf{0 . 8 5 7}$ \\
\hline France & 11.79 & 0.745 & 8.67 & 0.879 & $\mathbf{4 . 5 8}$ & $\mathbf{0 . 9 4 7}$ \\
\hline Germany & $\mathbf{0 . 1 7}$ & $\mathbf{0 . 8 9 7}$ & 1.40 & -0.123 & 1.01 & 0.149 \\
\hline Poland & $\mathbf{2 . 5 9}$ & $\mathbf{0 . 7 2 9}$ & 3.03 & 0.523 & 4.69 & 0.246 \\
\hline Sweden & $\mathbf{1 . 5 1}$ & 0.258 & 0.52 & 0.387 & 2.51 & $\mathbf{0 . 7 4 8}$ \\
\hline Greece & 54.46 & 0.511 & 49.20 & 0.335 & $\mathbf{2 9 . 2 3}$ & $\mathbf{0 . 9 1 5}$ \\
\hline Bulgaria & $\mathbf{1 2 . 5 1}$ & $\mathbf{0 . 7 7 8}$ & 41.82 & 0.284 & 59.37 & 0.440 \\
\hline Switzerland & 0.14 & 0.521 & $\mathbf{0 . 0 3}$ & $\mathbf{0 . 9 6 1}$ & 0.19 & 0.591 \\
\hline Finland & $\mathbf{0 . 2 3}$ & 0.861 & 0.38 & $\mathbf{0 . 9 0 1}$ & 0.45 & 0.794 \\
\hline Croatia & 8.58 & 0.889 & 6.61 & 0.884 & $\mathbf{4 . 1 6}$ & $\mathbf{0 . 9 8 9}$ \\
\hline Lithuania & $\mathbf{0 . 2 7}$ & $\mathbf{0 . 5 5 1}$ & 0.53 & 0.439 & 0.51 & 0.402 \\
\hline Latvia & 0.59 & 0.730 & $\mathbf{0 . 3 5}$ & $\mathbf{0 . 8 3 9}$ & 0.50 & 0.601 \\
\hline Romania & $\mathbf{0 . 6 9}$ & $\mathbf{0 . 6 9 1}$ & 101.82 & -0.130 & 102.85 & -0.332 \\
\hline Slovakia & $\mathbf{0 . 1 7}$ & $\mathbf{0 . 8 7 7}$ & 0.58 & -0.275 & 0.63 & 0.089 \\
\hline Turkey & $\mathbf{6 . 9 7}$ & $\mathbf{0 . 2 8 9}$ & 309.882 & -0.494 & 1044.43 & -0.050 \\
\hline \hline
\end{tabular}

Table 2. Pixel-calibrated (using GFED dataset) SFM performance in terms of modelled annual burned areas for the historical period 2000-2008 for selected countries. $r$ is Pearson's correlation coefficient, and MAE is the mean absolute error (in thousands of hectares). The indicators which are improved compared to the country-level GFED calibration (Table 1) are marked in bold.

\begin{tabular}{|l||r|r||}
\hline \multicolumn{1}{|c||}{} & \multicolumn{2}{l|}{ SFM vs GFED } \\
\hline \hline Country & \multicolumn{1}{|c|}{ MAE } & \multicolumn{1}{l|}{$\boldsymbol{r}$} \\
\hline \hline Italy & $\mathbf{3 1 . 5 8}$ & 0.383 \\
\hline Portugal & 97.72 & 0.765 \\
\hline Spain & 43.23 & 0.390 \\
\hline France & 9.50 & 0.875 \\
\hline Germany & $\mathbf{1 . 3 4}$ & $\mathbf{0 . 1 2 5}$ \\
\hline Poland & 3.08 & $\mathbf{0 . 5 2 7}$ \\
\hline Sweden & $\mathbf{0 . 4 6}$ & $\mathbf{0 . 6 3 2}$ \\
\hline Greece & 49.48 & $\mathbf{0 . 3 5 4}$ \\
\hline Bulgaria & 46.38 & 0.155 \\
\hline Switzerland & $\mathbf{0 . 0 3}$ & 0.938 \\
\hline Finland & 0.43 & 0.848 \\
\hline Croatia & 7.06 & 0.882 \\
\hline Lithuania & $\mathbf{0 . 5 3}$ & $\mathbf{0 . 4 5 9}$ \\
\hline
\end{tabular}




\begin{tabular}{|l||r|r||}
\hline Latvia & $\mathbf{0 . 3 4}$ & $\mathbf{0 . 8 5 0}$ \\
\hline Romania & $\mathbf{8 6 . 0 9}$ & $\mathbf{0 . 0 0 2}$ \\
\hline Slovakia & 0.98 & $-\mathbf{0 . 2 7 1}$ \\
\hline Turkey & 890.29 & -0.653 \\
\hline
\end{tabular}

Table 3. SFM performance (EFFIS- and GFED-calibrated) with modified fire probability function (5) in terms of modelled annual burned areas for the historical period 2000-2008 for selected countries. $r$ is Pearson's correlation coefficient, and MAE is the mean absolute error (in thousands of hectares). The indicators which are improved compared to Table 1 are marked in bold.

\begin{tabular}{|l||r|r||r|r||}
\hline \multicolumn{4}{|c|}{ SFM vs EFFIS } & \multicolumn{2}{l|}{ SFM vs GFED } \\
\hline \hline Country & \multicolumn{1}{|l|}{ MAE } & \multicolumn{1}{l|}{$\boldsymbol{r}$} & \multicolumn{1}{l|}{ MAE } & \multicolumn{1}{r|}{} \\
\hline \hline Italy & $\mathbf{2 2 . 6 7}$ & $\mathbf{0 . 8 5 6}$ & $\mathbf{2 9 . 2 9}$ & $\mathbf{0 . 6 1 8}$ \\
\hline Portugal & $\mathbf{7 6 . 2 0}$ & 0.756 & $\mathbf{8 4 . 1 8}$ & 0.770 \\
\hline Spain & 34.86 & 0.551 & 49.08 & 0.377 \\
\hline France & $\mathbf{9 . 1 1}$ & $\mathbf{0 . 9 0 1}$ & $\mathbf{7 . 1 3}$ & $\mathbf{0 . 9 7 3}$ \\
\hline Germany & $\mathbf{0 . 1 5}$ & $\mathbf{0 . 9 5 7}$ & 1.55 & $-\mathbf{0 . 0 4 4}$ \\
\hline Poland & 3.77 & 0.494 & 3.48 & 0.365 \\
\hline Sweden & 2.04 & $\mathbf{0 . 5 2 0}$ & $\mathbf{0 . 3 4}$ & $\mathbf{0 . 8 5 6}$ \\
\hline Greece & $\mathbf{4 5 . 1 8}$ & $\mathbf{0 . 6 6 9}$ & $\mathbf{4 4 . 0 9}$ & $\mathbf{0 . 4 9 1}$ \\
\hline Bulgaria & $\mathbf{8 . 4 1}$ & $\mathbf{0 . 8 6 2}$ & 63.79 & 0.214 \\
\hline Switzerland & 0.24 & $\mathbf{0 . 5 8 7}$ & $\mathbf{0 . 0 1}$ & $\mathbf{0 . 9 9 9}$ \\
\hline Finland & 0.54 & $\mathbf{0 . 8 8 4}$ & $\mathbf{0 . 3 5}$ & $\mathbf{0 . 9 1 9}$ \\
\hline Croatia & $\mathbf{3 . 7 6}$ & $\mathbf{0 . 9 8 5}$ & $\mathbf{2 . 3 3}$ & $\mathbf{0 . 9 8 6}$ \\
\hline Lithuania & 0.38 & $\mathbf{0 . 5 6 4}$ & 0.95 & $\mathbf{0 . 4 8 4}$ \\
\hline Latvia & 0.67 & $\mathbf{0 . 7 9 2}$ & 0.39 & $\mathbf{0 . 8 8 4}$ \\
\hline Romania & 1.10 & 0.627 & 145.21 & $-\mathbf{0 . 1 1 9}$ \\
\hline Slovakia & 0.28 & $\mathbf{0 . 9 2 8}$ & 0.81 & $\mathbf{- 0 . 1 5 3}$ \\
\hline Turkey & $\mathbf{6 . 3 4}$ & $\mathbf{0 . 5 2 3}$ & 459.44 & $\mathbf{- 0 . 3 1 3}$ \\
\hline
\end{tabular}

Table 4. Relative change between the SFM model with modified fire probability function (5) and the model with standard function (4) (for both EFFIS- and GFED-calibration). $r$ is Pearson's correlation coefficient, and MAE is the mean absolute error (in thousands of hectares). The indicators which are improved compared to Table 1 are marked in bold (lower MAE, higher $r$ ).

\begin{tabular}{|l||l|l||l|l||}
\hline \multicolumn{1}{|l|}{} & \multicolumn{2}{l||}{ SFM vs EFFIS } & \multicolumn{2}{l||}{ SFM vs GFED } \\
\hline \hline Country & $\Delta \mathrm{MAE}(\%)$ & $\Delta r(\%)$ & $\Delta$ MAE(\%) & $\Delta r(\%)$ \\
\hline \hline Italy & -20.1 & $\mathbf{2 7 . 4}$ & -9.2 & $\mathbf{2 9 . 6}$ \\
\hline Portugal & -9.4 & -1.4 & -13.6 & -0.2 \\
\hline Spain & 25.5 & -20.3 & 15.1 & -11.8 \\
\hline France & -22.7 & $\mathbf{2 0 . 9}$ & -17.7 & $\mathbf{1 0 . 8}$ \\
\hline Germany & $\mathbf{- 1 3 . 5}$ & $\mathbf{6 . 8}$ & 10.4 & -64.5 \\
\hline
\end{tabular}




\begin{tabular}{|l||l|l||l|l||}
\hline Poland & 45.9 & -32.3 & 14.8 & -30.3 \\
\hline Sweden & 35.3 & $\mathbf{1 0 1 . 4}$ & -33.6 & $\mathbf{1 2 1 . 4}$ \\
\hline Greece & $\mathbf{- 1 7 . 0}$ & $\mathbf{3 1 . 0}$ & $\mathbf{- 1 0 . 4}$ & $\mathbf{4 6 . 5}$ \\
\hline Bulgaria & $\mathbf{- 3 2 . 8}$ & $\mathbf{1 0 . 8}$ & 52.5 & -24.7 \\
\hline Switzerland & 74.3 & $\mathbf{1 2 . 6}$ & $\mathbf{- 8 2 . 5}$ & $\mathbf{4 . 0}$ \\
\hline Finland & 135.8 & $\mathbf{2 . 7}$ & $\mathbf{- 8 . 1}$ & $\mathbf{2 . 0}$ \\
\hline Croatia & -56.2 & $\mathbf{1 0 . 8}$ & $\mathbf{- 6 4 . 8}$ & $\mathbf{1 1 . 6}$ \\
\hline Lithuania & 39.5 & $\mathbf{2 . 3}$ & 80.8 & $\mathbf{1 0 . 3}$ \\
\hline Latvia & 14.4 & $\mathbf{8 . 4}$ & 12.3 & $\mathbf{5 . 3}$ \\
\hline Romania & 59.3 & -9.3 & 42.6 & $\mathbf{8 . 3}$ \\
\hline Slovakia & 62.1 & $\mathbf{5 . 8}$ & 38.3 & $\mathbf{4 4 . 2}$ \\
\hline Turkey & $-\mathbf{9 . 1}$ & $\mathbf{8 1 . 4}$ & 48.3 & $\mathbf{3 6 . 7}$ \\
\hline
\end{tabular}

Figures

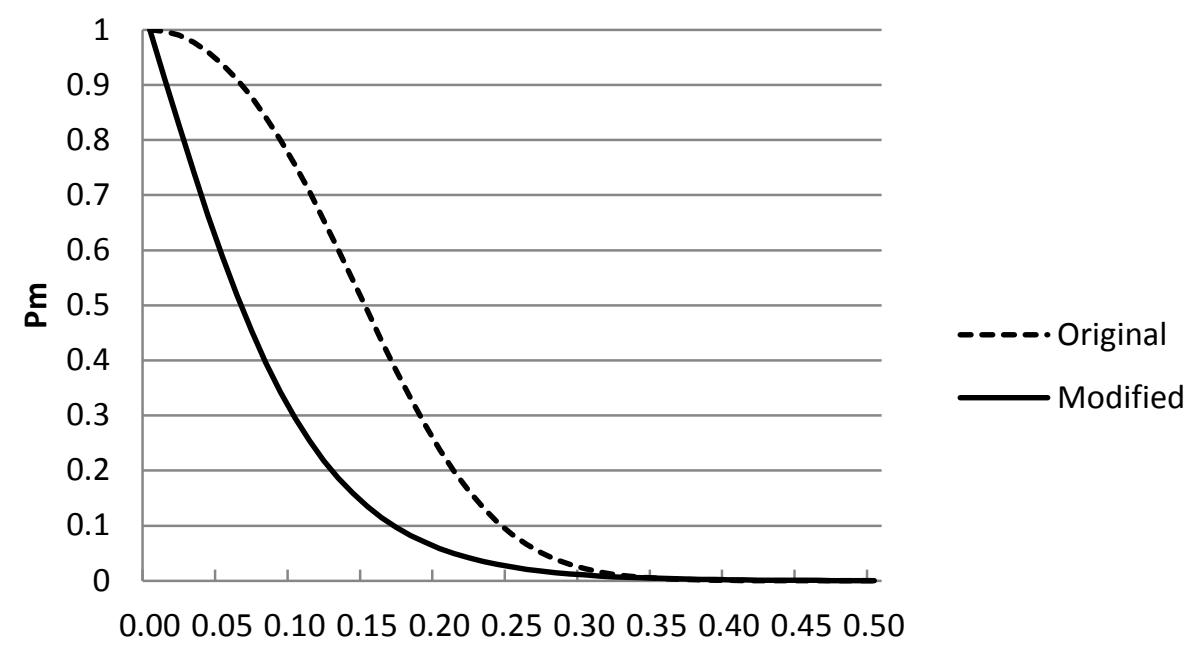

m

Figure 1. Fire probability functions $P_{m}$ reflecting fuel moisture $m$ : original (4) vs. modified (5).
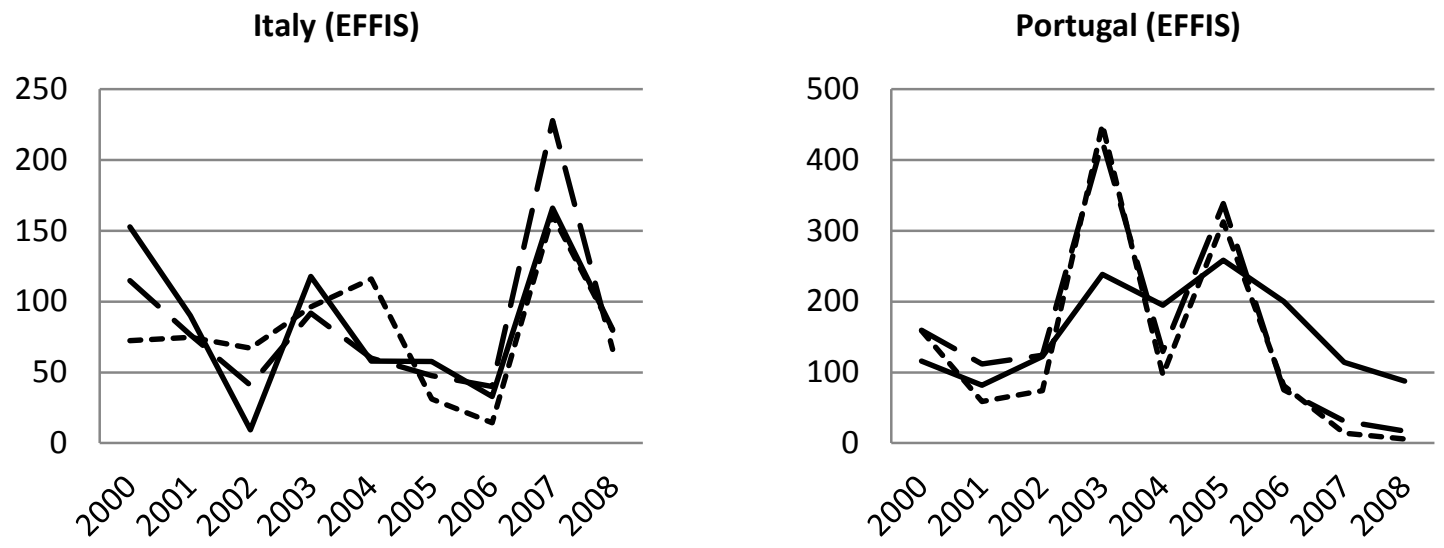
Spain (EFFIS)

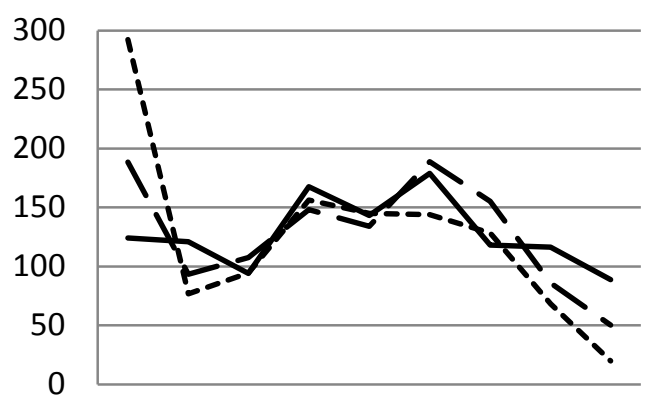

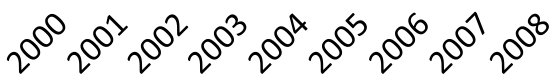

Germany (EFFIS)

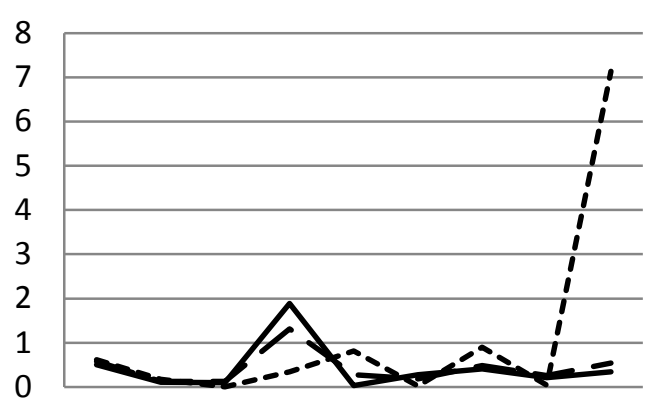

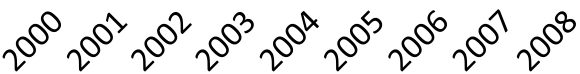

Sweden (GFED)

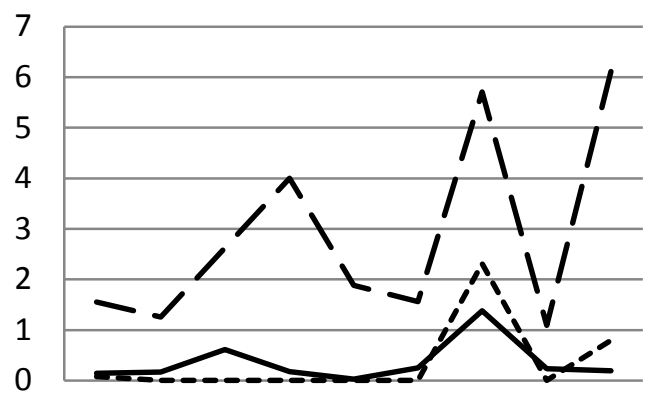

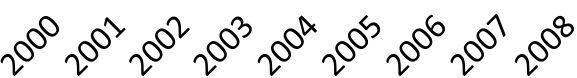

Bulgaria (EFFIS)

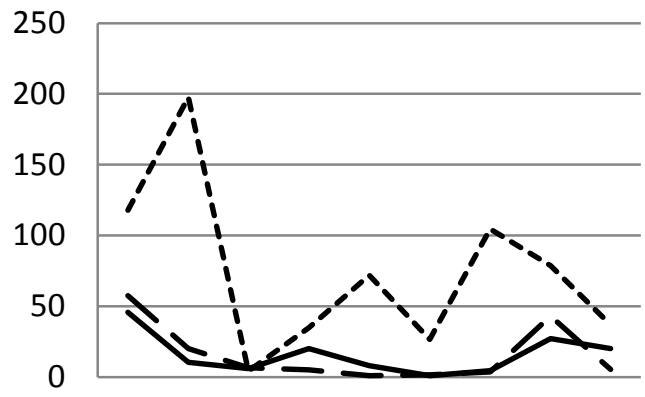

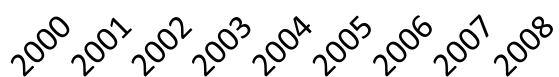

France (GFED)

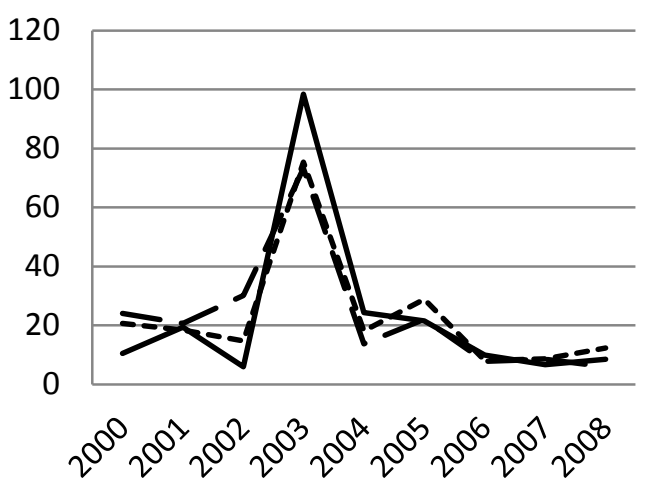

Poland (EFFIS)

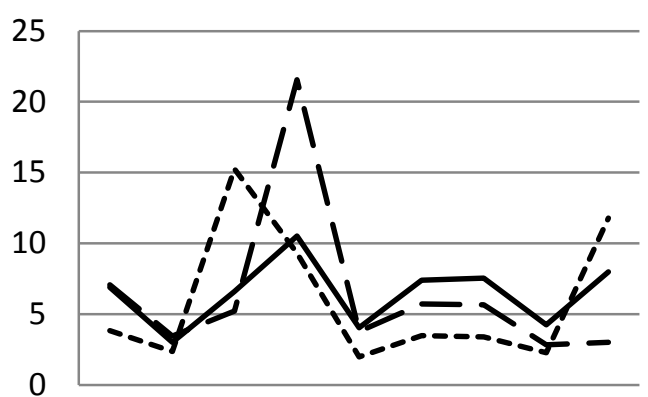

$\nu^{0^{0}} 2^{0^{2}} \nu^{0^{2}} \nu^{0^{3}} \nu^{0^{\alpha}} \nu^{0^{5}} \nu^{0^{6}} \nu^{0^{1}} \nu^{0^{8}}$

Greece (EFFIS)

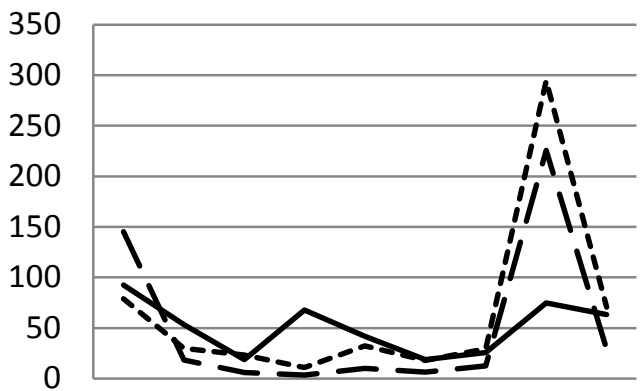

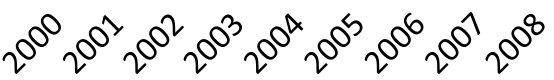

Switzerland (GFED)

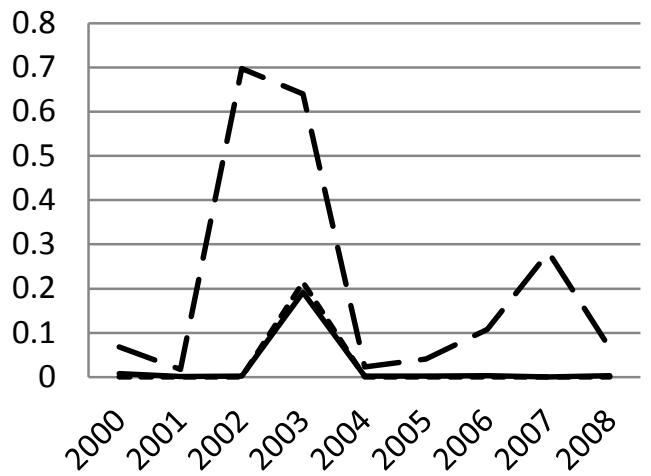


Finland (GFED)

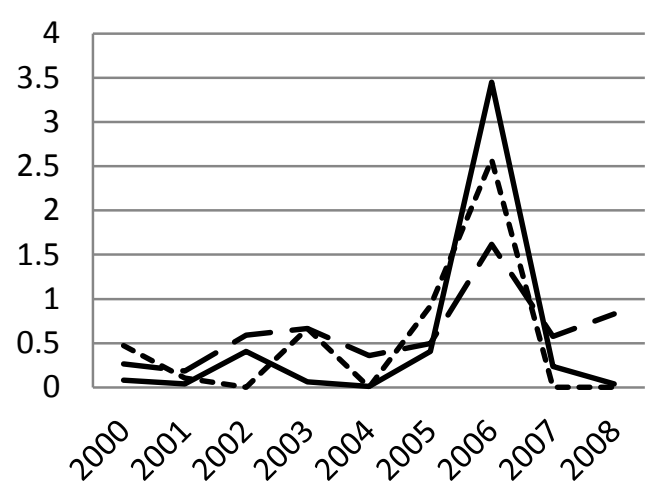

Lithuania (EFFIS)

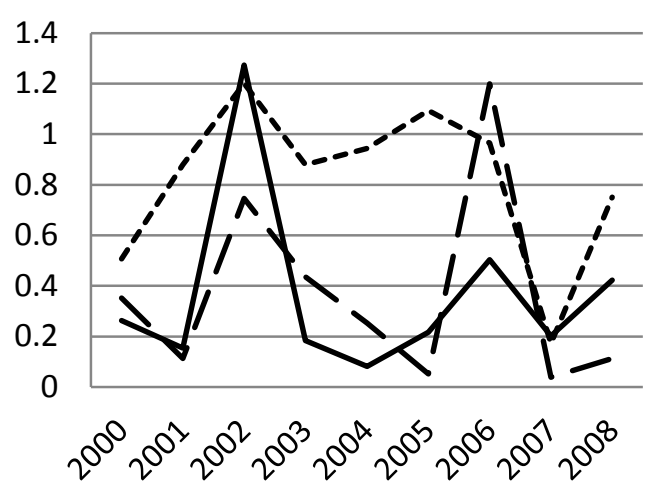

Romania (EFFIS)
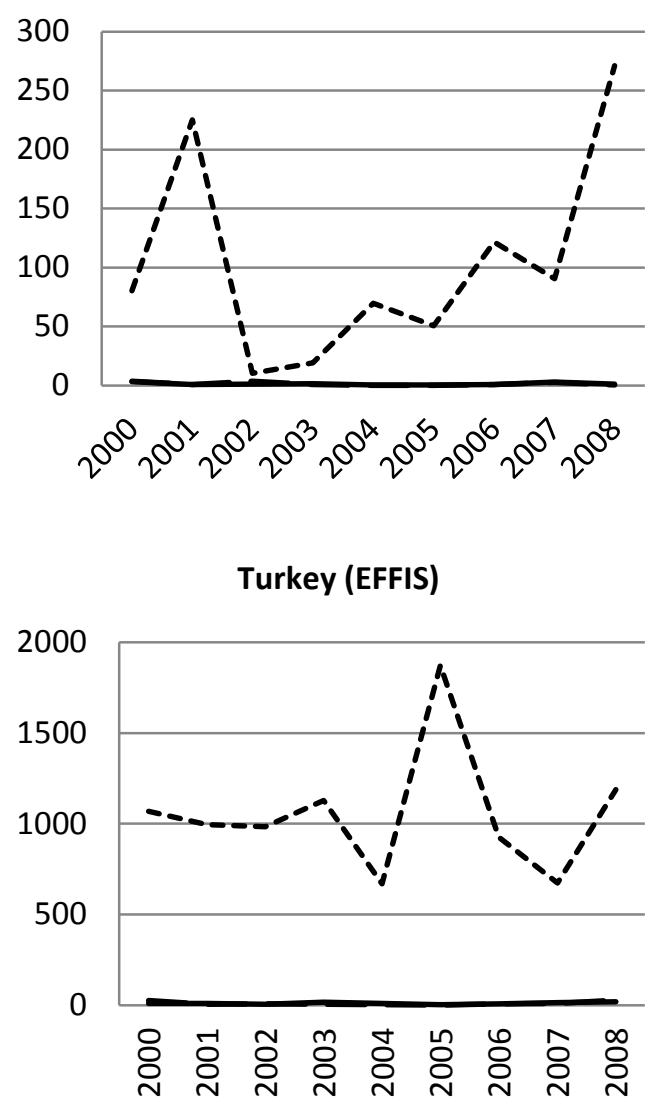

Croatia (GFED)

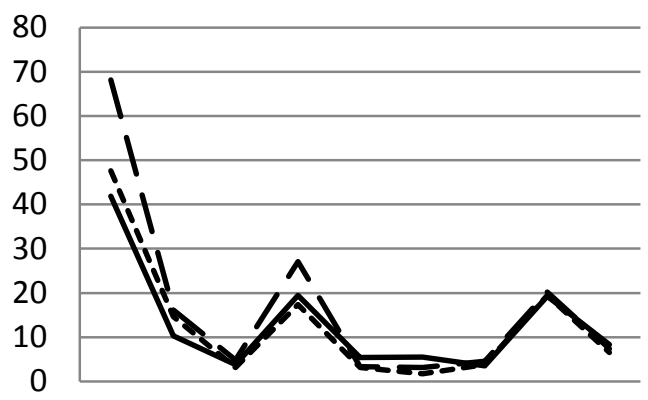

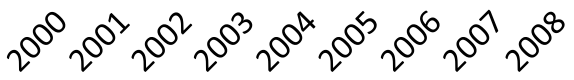

Latvia (GFED)

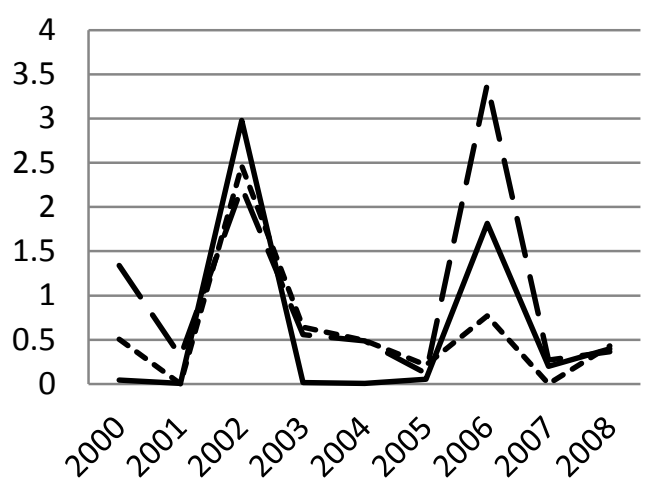

Slovakia (EFFIS)

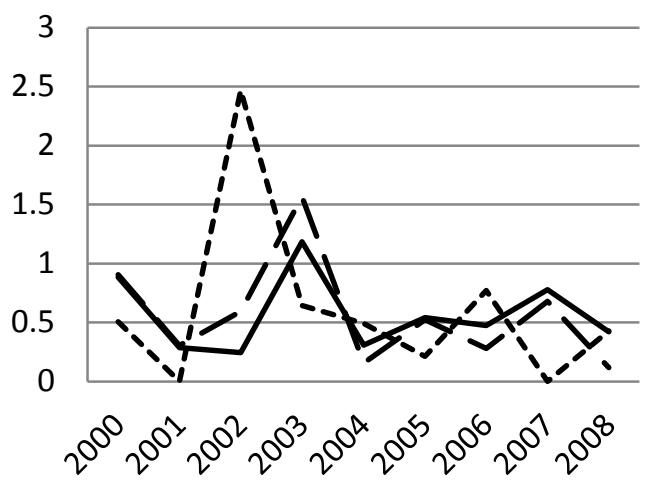

- - EFFIS

$\longrightarrow$ SFM

-----GFED 
Figure 2. Annual burned areas by country as reported by GFED and EFFIS, and modelled by SFM (in thousands of hectares). The source of the data used for the calibration of SFM is indicated in brackets on each plot. GFED, Global Fire Emissions Database; EFFIS, European Forest Fire Information System; SFM, Standalone Fire Model. 